\title{
Journal of Food \& Industrial Microbiology
}

\section{Antimicrobial Susceptibility Pattern of Staphylococcus aureus Isolates from Orthopaedic Patients in Abuth, Zaria}

\author{
Onaolapo JA1 , Olayinka BO ${ }^{1}$, Adeshina $\mathrm{GO}^{1}$, Igwe $\mathrm{JC}^{2}$ and Obajuluwa $\mathrm{AF}^{1 *}$ \\ ${ }^{1}$ Department of Pharmaceutics and Pharmaceutical Microbiology, Ahmadu Bello University, Zaria, Nigeria \\ ${ }^{2}$ National Biotechnology Development Agency, Abuja
}

*Corresponding author: Obajuluwa AF, Department of Pharmaceutics and Pharmaceutical Microbiology, Ahmadu Bello University, Zaria, Nigeria, Tel: +234 803800 2812; E-mail: funkeyomi6874@gmail.com

Rec date: Sep 30, 2015, Acc date: Jan 18, 2016, Pub date: Jan 22, 2016

Copyright: (C) 2016 Onaolapo JA, et al. This is an open-access article distributed under the terms of the Creative Commons Attribution License, which permits unrestricted use, distribution, and reproduction in any medium, provided the original author and source are credited.

\begin{abstract}
As Staphylococcus aureus remain the predominant microbial flora of the human respiratory tract and skin; it also account for the most human integumental infections and life-threatening systemic diseases especially in orthopaedic surgical site infections (SSIs). This study evaluates the antibiotics susceptibility pattern of Staphylococcus aureus isolates from orthopaedic patients to various antimicrobial agents used in the treatment of surgical sites infection in Ahmadu Bello University Teaching Hospital (ABUTH), Zaria, Nigeria. A total of 100 clinical swab samples of surgical sites were collected from orthopaedic patients in ABUTH, Zaria, Nigeria out of which 39 were identified as Staphylococcus aureus using API STAPH identification kit. Disc agar diffusion method was used for the antibiotics susceptibility test while nitrocefin microplate assay was used to test for beta lactamase production. Our findings showed that $97.4 \%$ of the isolates were susceptible to both vancomycin and gentamicin followed by ciprofloxacin (94.9\%) and pefloxacin (84.6\%). The isolates were highly resistant to ampicilin (94.9\%), ceftriaxone $(79.5 \%)$, cefoxitin $(64.1 \%)$ and amoxicillin-clavulanic acid $(59 \%)$ which is beta-lactam antibiotics. Further evaluation showed that $64 \%$ of the isolates produced beta-lactamase, while $36 \%$ do not. We conclude that the Staphylococcus aureus isolates from orthopaedic patients in ABUTH, Zaria were highly resistant to beta lactam antibiotics used in this study.
\end{abstract}

\section{Key words:}

Staphylococcus aureus, susceptibility; ABUTH; Zaria

Orthopaedic patients; Antibiotic

\section{Introduction}

Staphylococcus aureus is commonly carried on the skin or in the nose of healthy individuals. It is an important pathogen in human infections causing illness ranging from minor skin infections and abscesses to life - threatening diseases such as pneumonia, meningitis, endocarditis, toxic shock syndrome and septicaemia which may be rapidly fatal [1]. Bacterial resistance to antibiotics has been recognized since the first drugs were introduced for clinical use. Penicillin was first introduced in 1941, when less than $1 \%$ of Staphylococcus aureus strains were resistant to its action. By 1947, 38\% of hospital strains had acquired resistance and currently over $90 \%$ of Staphylococcus aureus isolates are resistant to penicillin. Increasing resistance to antibiotics is a consequence of selective pressure [2]. In orthopaedics, S. aureus has been implicated in surgical site infection, painful infection of joint fluid known as septic or infective arthritis, post-operative infection, implant devices, infection following trauma, chronic osteomyelitis subsequent to an open fracture, meningitis following skull fracture. This study was aimed at determining the antibiotic susceptibility pattern of the $\mathrm{S}$. aureus isolates from orthopaedic patients in a tertiary hospital in North-western Nigeria.

\section{Methodology}

\section{Sample collection}

One hundred clinical samples were collected aseptically from the wound, skin and bed of orthopaedic patients in Ahmadu Bello University Teaching Hospital Zaria, Nigeria over a period of 5 months. Ethical approval and patients' consent were obtained.

\section{Identification of $S$. aureus isolates}

API STAPH identification kit (bioMerieux, Inc, Durham, USA) was used to identify the $\mathrm{S}$. aureus isolates. The procedures were carried out according to the manufacturer's instructions.

\section{Antibiotic susceptibility test}

Disk diffusion tests was performed for each of the isolates previously identified as $S$. aureu follow the method recommended by the Clinical Laboratory Standard Institute [3]. List of antibiotics used are: Cefoxitin $30 \mu \mathrm{g}$, Ceftriaxone $30 \mu \mathrm{g}$, Vancomycin $30 \mu \mathrm{g}$, Ampicillin $10 \mu \mathrm{g}$, Gentamicin $10 \mu \mathrm{g}$, Pefloxacin $5 \mu \mathrm{g}$, Ciprofloxacin $5 \mu \mathrm{g}$, Amoxicillin-clavulanic acid $30 \mu \mathrm{g}$, Erythromycin $15 \mu \mathrm{g}$ and Clindamycin $2 \mu \mathrm{g}$ (Oxoid Ltd. Basingstoke, London).

\section{Test for $\boldsymbol{\beta}$-lactamase production (Nitrocefin test)}

Enzyme extracts of the S. aureus isolates were prepared as described by Caddick [4] with modification. Microplate Nitrocefin assay was carried out as follows: $1 \mathrm{mg}$ lyophilized Nitrocefin powder (Oxoid, UK) was reconstituted in $1.9 \mathrm{ml}$ of $0.1 \mathrm{M}$ phosphate buffer, $\mathrm{pH} 7$ 
Citation: Onaolapo JA, Olayinka BO, Adeshina GO, Igwe JC, Obajuluwa AF (2016) Antimicrobial Susceptibility Pattern of Staphylococcus aureus Isolates from Orthopaedic Patients in Abuth, Zaria. J Food Ind Microbiol 2: 106.

Page 2 of 6

supplied by the manufacturer. The reconstituted nitrocefin was further diluted 1 in 10 with PBS to give $50 \mu \mathrm{g} / \mathrm{ml}$ solution. The disrupted cell preparations were used immediately by dispensing $50 \mu \mathrm{L}$ of preparation into separate wells of a 96 well plate. $50 \mu \mathrm{L}$ of diluted nitrocefin solution was added into each of the wells and incubated at $37^{\circ} \mathrm{C}$ for 10 minutes. In the presence of $\beta$-lactamase, the chromogenic nitrocefin substrate changes colour from yellow to pink/red.

\section{Determination of multiple antibiotics resistance (MAR) index}

The Multiple Antibiotic Resistance (MAR) index was determined for each isolate by dividing the number of antibiotics to which the organisms is resistant to by the total number of antibiotics tested [5-7].

\section{Results}

A total number of 100 samples were collected and the distribution of S. aureus from the sample sites is presented in Table 1 .

\begin{tabular}{|l|l|l|}
\hline Source & No of sample & S. aureus No (\%) \\
\hline Wound & 22 & $6(27.3)$ \\
\hline Skin & 43 & $16(37.2)$ \\
\hline Bed & 35 & $17(48.6)$ \\
\hline Total & 100 & $39(39.0)$ \\
\hline
\end{tabular}

Table 1: Distribution of $S$. aureus isolates.

Antibiotic Susceptibility Pattern of isolates

A high percentage $(97.4 \%)$ of isolates were susceptible to both vancomycin and gentamicin followed by ciprofloxacin $(94.9 \%)$ and pefloxacin $(84.6 \%)$. The level of resistance of the S. aureus isolates to antibiotics is as follows: ampicilin (94.9\%), ceftriaxone (79.5\%), cefoxitin (64.1\%) and amoxicillin - clavulanic acid (59\%) Table 2.

\begin{tabular}{|l|l|l|l|}
\hline Antibiotics & Sensitive & Intermediate & Resistant \\
\hline No of sample $(\%) \mathrm{n}=39$ & $2(5.1)$ & 0 & $37(94.9)$ \\
\hline Ampicillin $10 \mu \mathrm{g}$ & $8(20.5)$ & $13(33.3)$ & $18(46.2)$ \\
\hline Ceftriaxone $30 \mu \mathrm{g}$ & $14(35.9)$ & 0 & $25(64.1)$ \\
\hline Cefoxitn $30 \mu \mathrm{g}$ & $16(41.0)$ & 0 & $23(59.0)$ \\
\hline Amoxicillin-clavulanic acid 30 $\mathrm{\mu g}$ & $12(30.8)$ & $13(33.3)$ & $14(35.9)$ \\
\hline Clindamycin $2 \mu \mathrm{g}$ & $19(48.7)$ & $10(25.6)$ & $10(25.6)$ \\
\hline Erythromycin $15 \mu \mathrm{g}$ & $33(84.6)$ & 0 & $6(15.4)$ \\
\hline Pefloxacin $5 \mu \mathrm{g}$ & $38(97.4)$ & 0 & $1(2.6)$ \\
\hline Vancomycin $30 \mu \mathrm{g}$ & $37(94.9)$ & $2(5.1)$ & 0 \\
\hline Ciprofloxacin $5 \mu \mathrm{g}$ & & & \\
\hline
\end{tabular}

\begin{tabular}{|l|l|l|l|}
\hline Gentamicin $10 \mu \mathrm{g}$ & $38(97.4)$ & 0 & $1(2.6)$ \\
\hline
\end{tabular}

Table 2: Percentage susceptibility of $S$. aureus isolates.

Beta lactamase Test and their Resistant Pattern to Antibiotic

The result of the beta lactamase test is shown in Figure 1.

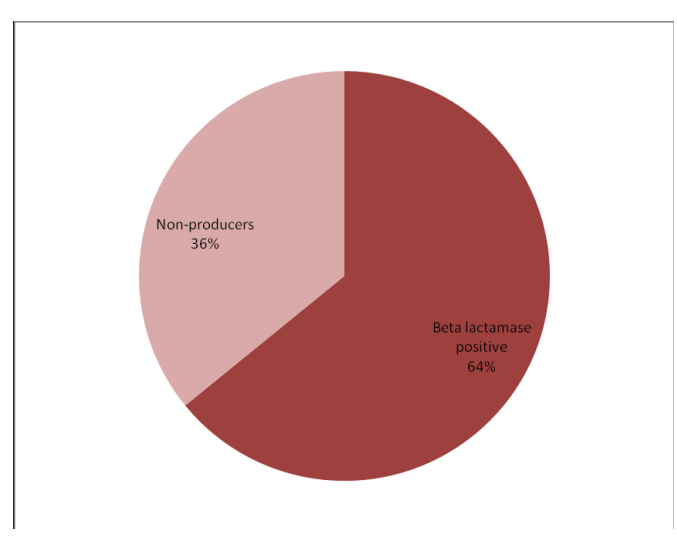

Figure 1: Beta lactamase production by $S$. aureus isolates.

Resistant Pattern of beta lactamase Producing $S$. aureus

The resistant patterns of beta lactamase producing $S$. aureus isolates to antibiotics are presented in Figure 2. There it was observed that these beta lactamase producing isolates were generally resistant to ampicillin (96\%), ceftriaxone (88\%), cefoxitin (76\%) and amoxicillin clavulanate $(68 \%)$ which are beta lactam antibiotics.

Multiple Antibiotic Resistant (MAR) Index

\begin{tabular}{|l|l|}
\hline MAR & S. aureus isolates $(\mathbf{n}=39)$ \\
\hline 0.1 & $4(10.3)$ \\
\hline 0.2 & $3(7.7)$ \\
\hline 0.25 & $2(5.1)$ \\
\hline 0.3 & $4(10.3)$ \\
\hline 0.4 & $5(12.8)$ \\
\hline 0.5 & $9(23.1)$ \\
\hline 0.6 & $8(20.5)$ \\
\hline 0.7 & $2(5.1)$ \\
\hline 0.8 & $1(2.6)$ \\
\hline 0.9 & $1(2.6)$ \\
\hline
\end{tabular}

Table 3: Result of multiple antibiotic resistant (MAR) index for $S$. aureus solates antibiotics resistance pattern of $S$. Aureus. 
Citation: Onaolapo JA, Olayinka BO, Adeshina GO, Igwe JC, Obajuluwa AF (2016) Antimicrobial Susceptibility Pattern of Staphylococcus aureus Isolates from Orthopaedic Patients in Abuth, Zaria. J Food Ind Microbiol 2: 106.

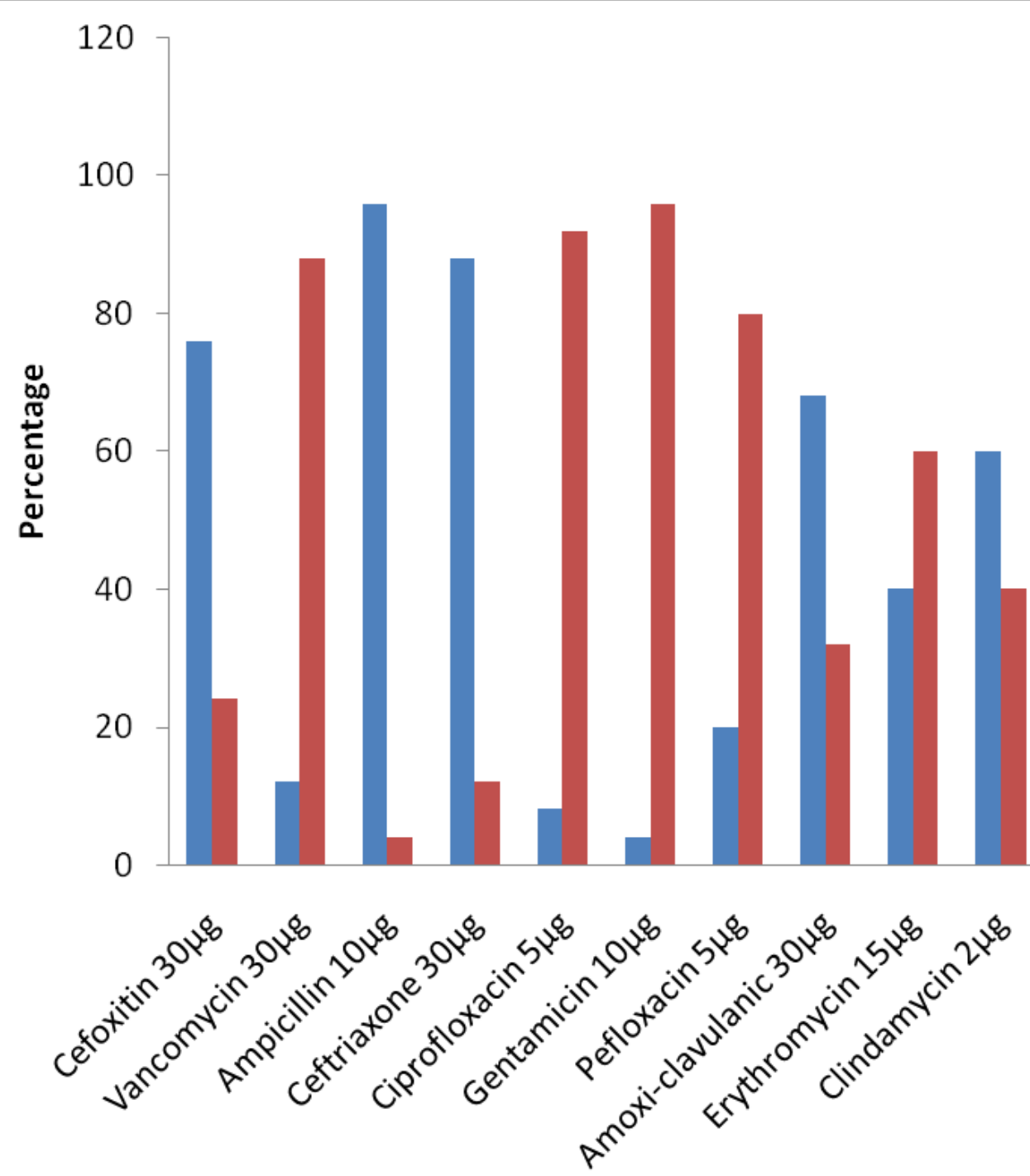

Antibiotics

Figure 2: Resistance pattern of beta - lactamase producing $S$. aureus to antibiotics.

The result of the MAR index of the S. aureus showed that 32(82.1\%) of the resistant $S$. aureus isolates had MAR index greater than 0.2 , details are shown Table 3.

This result showed that 50\% (19) of the isolated Staph. aureus were multidrug resistant (MDR) and $28 \%$ (11) were extensively drug resistant (XDR). The isolates were observed to show a concurrent pattern of resistance to Cephalosporine, Macrolide and Betalactame/ Betalactame inhibitors (21\%) while $10 \%$ (4) showed resistance to Cephalosporine, Betalactame/Betalactame inhibitors and Fluoroquinolones.

\section{Discussion}

$S$. aureus is known to be one of the causes of nosocomial infection [8-10], the isolation of $S$. aureus from the patients' beddings in this study is in support of this. The majority of nosocomial infection is caused by the patient's own endogenous microbial flora present upon admission to the hospital [11]. The $97.4 \%$ susceptibility to gentamicin observed in this study is consistent with previous reports from Africa $[12,13]$ Gentamicin is an example of aminoglycoside whose mode of action is to inhibit protein synthesis by inhibiting $30 \mathrm{~S}$ ribosome of the organism [14]. High susceptibity to vancomycin was observed in this study. Vancomycin is a glycopeptide which inhibits peptidoglycan synthesis in the bacteria, it is a known drug of choice in the treatment of methicillin resistant $S$. aureus [15] 
Citation: Onaolapo JA, Olayinka BO, Adeshina GO, Igwe JC, Obajuluwa AF (2016) Antimicrobial Susceptibility Pattern of Staphylococcus aureus Isolates from Orthopaedic Patients in Abuth, Zaria. J Food Ind Microbiol 2: 106.

Page 4 of 6

Ciprofloxacin is a quilonone which acts by inhibition of enzymes involved in DNA replication and function, the $94.9 \%$ susceptibility of $S$. aureus observed in this study is in conformity with previous reports [16-18]. The little level of resistance to ciprofloxacin observed in this study might be connected with the increasing rate of availability of different cheap brands of generic ciprofloxacin in the market which might have probably led to the misuse of it.

The $S$. aureus isolates in this study were generally resistant to penicillins as was shown by the resistance pattern of the beta lactamase producing $S$. aureus isolates in Figure 2. Beta lactamase hydrolyses the amide bond of the $\beta$-lactam ring resulting in an inactive compound. Some researchers found penicillins to have the highest rate of resistance to clinical samples especially $S$. aureus. [19,20]. Penicillins inhibit bacterial cell wall synthesis [21], $S$. aureus develop resistance to penicillins by the production of beta lactamases and by permmeabilty barrier of the cell surface [22].

The high percentage of the $S$. aureus having MAR index greater than 0.2 (Tables 3 ) suggests that the isolates originated from a high risk source of contamination where antibiotics are often used [6,7]. It also indicates that a large proportion of the bacterial isolates have been exposed to several antibiotics. The high incidence of multi drug resistance observed in this study (Table 4) could be attributed to a combination of microbial characteristics such as selective pressure on antimicrobial usage, societal and technological changes that enhance the transmission of drug resistant organisms [23]. Other reasons could be due to increase in irrational consumption rate of antibiotics, transmission of resistant isolates between people, self-medication, non-compliance with medication and sales of substandard drug.

\begin{tabular}{|c|c|c|c|c|}
\hline $\mathbf{S} / \mathbf{N}$ & Isolates & Antibiotics Resistant Pattern & CART & LR \\
\hline 1 & W4 & AMP & BT & NIL \\
\hline 2 & W7a & FOX, AMP, CRO, ERY, DA, AMC & CEP, BT, MAC, LIN & MDR \\
\hline 3 & W7b & FOX, AMP, CRO, AMC & CEP, BT & XDR \\
\hline 4 & W20 & FOX, AMP, CRO, AMC & CEP, BT & XDR \\
\hline 5 & W39 & FOX, AMP, CRO, VA & CEP, BT, MAC, GL & MDR \\
\hline 6 & W51 & FOX, AMP, DA, AMC & CEP, BT, LIN & MDR \\
\hline 7 & S1 & DA & LIN & NIL \\
\hline 8 & S2 & FOX, AMP, AMC, ERY, DA & CEP, BT, MAC, LIN & MDR \\
\hline 9 & S8 & AMP & BT & NIL \\
\hline 10 & S12 & FOX, AMP, CRO, AMC, VA & CEP, BT, GL & MDR \\
\hline 11 & S20 & FOX, AMP, CRO, AMC & CEP, BT & $\mathrm{XDR}$ \\
\hline 12 & S23 & AMP, ERY, DA & BT, MAC, LIN & MDR \\
\hline 13 & S24 & FOX, AMP, CRO, AMC, ERY, DA & CEP, BT, MAC, LIN & MDR \\
\hline 14 & S25 & AMP, DA & $\mathrm{BT}, \mathrm{LIN}$ & XDR \\
\hline 15 & S27 & FOX, AMP, CRO, AMC, VA & CEP, BT, GL & MDR \\
\hline 16 & S41 & FOX, AMP, CRO, AMC & CEP, BT & XDR \\
\hline 17 & S46 & FOX, AMP, CRO, AMC, VA, PER & CEP, BT, GL, FLU & MDR \\
\hline 18 & S47 & DA & LIN & NIL \\
\hline 19 & S51 & FOX, AMP, AMC & CEP, BT & $\mathrm{XDR}$ \\
\hline 20 & S55 & FOX, AMP, PER, AMC & CEP, BT, FLU & MDR \\
\hline 21 & S58 & AMP & BT & NIL \\
\hline 22 & S72 & AMP, DA & CEP, BT, MAC, LIN & MDR \\
\hline 23 & B1 & AMP, CRO, ERY, DA & CEP, BT, MAC, LIN & MDR \\
\hline 24 & B7 & AMP & BT & NIL \\
\hline 25 & B8 & AMP & BT & NIL \\
\hline 26 & B13 & FOX, AMP, CRO, AMC, VA & CEP, BT, GL & MDR \\
\hline
\end{tabular}


Citation: Onaolapo JA, Olayinka BO, Adeshina GO, Igwe JC, Obajuluwa AF (2016) Antimicrobial Susceptibility Pattern of Staphylococcus aureus Isolates from Orthopaedic Patients in Abuth, Zaria. J Food Ind Microbiol 2: 106.

Page 5 of 6

\begin{tabular}{|l|l|l|l|l|}
\hline 27 & B16 & FOX, AMP, AMC, ERY & CEP, BT, MAC & MDR \\
\hline 28 & B20 & FOX, AMP, CRO & CEP, BT & XDR \\
\hline 29 & B26 & FOX, AMP, CRO, AMC & CEP, BT & XDR \\
\hline 30 & B35 & FOX, AMP, CRO, AMC & CEP, BT & XDR \\
\hline 31 & B47 & FOX, AMP, CRO, AMC & CEP, BT & XDR \\
\hline 32 & B49 & FOX, AMP, AMC & CEP, BT & XDR \\
\hline 33 & B50 & AMP, ERY, DA & BT, MAC, LIN & MDR \\
\hline 34 & B55 & FOX, AMP, AMC, PEF & CEP, BT, FLU & MDR \\
\hline 35 & B60 & AMP, ERY, DA & BT, MAC, LIN & MDR \\
\hline 36 & B62 & AMP & BT & NIL \\
\hline 37 & B69 & FOX, AMP, CRO, AMC, ERY, DA & CEP, BT, MAC, LIN & MDR \\
\hline 38 & B77 & FOX, AMP, CRO, PEF & CEP, BT, FLU & MDR \\
\hline $\begin{array}{l}\text { Key: Lincosamides (LIN), Cephalosporine (CEP), Macrolide (MAC), Betalactame/ Betalactame Inhibitors (BT), Glycopeptide (GL), Fluoroquinolone (FLU), Class of } \\
\text { antibiotics resistant to (CART), Level of resistance (LR), Cefoxitin (FOX) Vancomycin (VA), Ampicillin (AMP), Ceftriaxone (CRO), Ciprofloxacin (CIP), Gentamicin (CN), } \\
\text { Pefloxacin (PEF), Erythromycin (ERY), Amoxicillin-clavulanic acid (AMC), Clindamycin (DA) }\end{array}$ & \\
\hline
\end{tabular}

Table 4: Antibiotic resistance pattern of the isolated $S$. aureus.

\section{Conclusion}

High susceptibility S. aureus isolates to gentamicin and ciprofloxacin was observed in this study, this is an indication that these antibiotics can be used for empirical treatment of infections from orthopaedic patients in this hospital since vancomycin is not readily available in this community. The $\mathrm{S}$. aureus isolates were highly resistant to beta lactam antibiotics. The abuse of beta-lactam antibiotics and other classes of antibiotics in our community should therefore be controlled.

\section{References}

1. Holmes A, Ganner M, McGuanes, Pitt TL, Cookson BD, et al. (2005) Staphlococcus aureus isolates carrying Panton- Valentine leucocidin genes in England and Wales: frequency. Characterization, and association with clinical disease. Journal of Clinical Microbiology 43: 2384-2390.

2. Power EGM (1998) Bacteria Resistance to antibiotics. In: Hugo WB, Russel AD (6thedn.), Pharmaceutical Microbiology, Edinburgh, Blackwell Scientific Publications, London: 181-197.

3. Clinical and Laboratory Standards Institute (2007) Performance standards for antimicrobial susceptibility testing. 17th informational supplement. CLSI, Wayne, PA. CLSI : M100-S17.

4. Caddick JM (2005) Molecular typing of hospital-acquired, community acquired and multi-drug resistant methicillin -resistant Staphylococcus aureus. PhD Thesis Aston University, Birmingham.

5. Krumperman PH (1983) Multiple antibiotic resistance indexing of Escherichia coli to identify high-risk sources of fecal contamination of foods. Appl Environ Microbiol 46: 165-170.

6. Paul S, Bezbaruah RL, Roy MK, Ghosh AC (1997) Multiple antibiotic resistance (MAR) index and its reversion in Pseudomonas aeruginosa. Lett Appl Microbiol 24: 169-171.

7. Christopher AJ, Hora S, Ali Z (2013) Investigation of plasmid profile, antibiotic susceptibility pattern multiple antibiotic resistance index calculation of Escherichia coli isolates obtained from different human clinical specimens at tertiary care hospital in Bareilly-India. Annals of Tropical Medicine and Public Health 6: 285-289.
8. Narezkina A, Edelstein I, Dekhnich A, Stratchounski L, Pimkin M, et al. (2006) Prevalence of methicillin - resistant Staphylococcus aureus in different regions of Russia: results of multicenter study. 12th European Congress of Microbiology and Infectious Diseases.

9. Naidu K, Nabose I, Ram S, Viney K, Graham SM, et al. (2014) A descriptive study of nosocomial infections in an adult intensive care unit in fiji: 2011-12. J Trop Med 2014: 545160.

10. Sugata D, Soumi D, Neeraj S, Avijit H (2015) Nosocomial infection in the intensive care unit: Incidence, risk factors, outcome and associated pathogens in a public tertiary teaching hospital of Eastern India. Indian J Crit Care Med 19: 14-20.

11. Arif MA, Shahid AA, Shazia A, Irfan M (2007) Nosocomial infections due to methicillin - resistant Staphylococcus aureus in hospital patients. Pak J Med Sci 23: 593-596.

12. Onanuga A, Temedie TC (2011) Nasal carriage of multi-drug resistant Staphylococcus aureus in healthy inhabitants of Amassoma in Niger delta region of Nigeria. African Health Sciences 11: 176-181.

13. Umolu PI, Okoli EN, Izomoh IM (2002) Antibiogram and B lactamase production of Staphylococcus aureus isolates from different human clinical specimens in Edo state, Nigeria. West Afr Med 21: 124-127.

14. Jawetz E (1992) Principles of Antimicrobial Drug Action. In: Katzung BG, Basic and clinical pharmacology (5thedn). Prentice Hall International Inc: 617-625.

15. Haddadin AS, Fappiano SA, Lipsett PA (2002) Methicillin resistant Staphylococcus aureus (MRSA) in the intensive care unit. Postgrad Med J 78: 385-392.

16. Akerele J, Abhulimen P, Okonofua F (2001) Prevalence of asymptomatic bacteriuria among pregnant women in Benin City, Nigeria. J Obstet Gynaecol 21: 141-144.

17. Ehinmidu J (2003) Antibiotic susceptibility patterns of urine bacterial isolates in Zaria, Nigeria. Trop J Pharm Res 2: 223-228.

18. Onanuga A, Oyi AR, Olayinka BO, Onaolapo JA (2005) Prevalence of community-associated methicillin-resistant Staphylococcus aureus among healthy women in Abuja, Nigeria. African J Biotechnology 4: 942-945. 
Citation: Onaolapo JA, Olayinka BO, Adeshina GO, Igwe JC, Obajuluwa AF (2016) Antimicrobial Susceptibility Pattern of Staphylococcus aureus Isolates from Orthopaedic Patients in Abuth, Zaria. J Food Ind Microbiol 2: 106.

Page 6 of 6

19. Nwankwo EO, Nasiru MS (2011) Antibiotic sensitivity pattern of Staphylococcus aureus from clinical isolates in a tertiary health institution in Kano, Northwestern Nigeria. Pan Afr Med J 8: 4.

20. Cohen ML (1992) Epidemiology of drug resistance: implications for a post-antimicrobial era. Science 257: 1050-1055.

21. Russell AD (2004) Types of Antibiotics and Synthetic Antimicrobial Agents in Denyer SP, Hodges NA, Gorman SP (Edn) Hugo and Russell's Pharmaceutical Microbiology 7th edition Blackwell Science Ltd: 152-178.
22. Pichichero ME (2005) A review of evidence supporting the American Academy of Pediatrics recommendation for prescribing cephalosporin antibiotics for penicillin-allergic patients. Pediatrics 115: 1048-1057.

23. Orozova P, Chikova V, Kolarova V, Nenova R, Konovska M, et al. (2008) Antibiotic resistance of potentially pathogenic Aeromonas strains. Trakia Journal of Sciences 6: 71-78. 